\title{
INFLUENCE OF THE FATIGUE LOAD LEVEL AND THE HOLE DIAMETER ON THE LAMINATE STRUCTURE'S FATIGUE PERFORMANCE
}

\author{
Malgorzata Zalewska \\ Institute of Aviation, Warsaw, Poland \\ malgorzata.zalewska@ilot.edu.pl
}

\begin{abstract}
Damage tolerance of composite aircraft structure is one of the main areas of research, important when a new product is being developed. There are a number of variables, such as damage characteristics (dent depth, delamination area) and loading parameters (load type, amplitude of cyclic loading, load sequence) that need to be investigated experimentally [1]. These tests of composite materials are usually performed at an element level and are carried out in order to validate the analytical model, developed to predict the full-scale component's behaviour. The paper presents the results of compression testing of the [36/55/9] carbon fibrelepoxy laminate, manufactured with the Automated Fibre Placement technology (AFP) and subjected to static and fatigue loads. The laminate compression loading mode was achieved through sandwich 4-point flexure. At the stage of fatigue testing, two parameters were investigated: the damage size, simulated by the hole diameter and the fatigue load level. Based on the test results, the laminate fatigue load limit equal to $75 \%$ of the OHC failure load was evaluated. By collating the static and fatigue tests results, the damage tolerance characteristic of the considered laminate was created.
\end{abstract}

Keywords: composite, fatigue, damage

\section{INTRODUCTION}

The current methodology used for a new composite product development is based on the program of analysis and tests, commonly known as the Building Block Approach [2]. It involves the analysis and the serial testing of the 
coupons of increasing complexity. The objective at a coupon level testing is to determine material properties and to generate allowables. At the element level testing, the structural design details, such as the laminate stacking sequence, are evaluated. A lot of tests at this level concern damage tolerance investigation, and are performed in order to validate the analytical models, and to demonstrate that the composite structure is capable of withstanding the design loads. The scaling issue is one of the main challenges encountered at this stage of product development.

The purpose of this study was to access the static and fatigue performance of a certain carbon fiber/epoxy laminate subjected to compressive loads and to develop a methodology for the laminate damage tolerance evaluation. Two variables were analyzed: the amplitude of cyclic loads and the damage area characterized by the hole diameters. In further test programs, the other factors including impact damage characteristics and loading parameters shall be verified. The obtained experimental data will support the development of the composite structures currently developed by the Institute of Aviation.

\section{TEST METHOD SELECTION AND ELEMENT DESIGN}

Apart from the ASTM D7137 test method used for testing relatively small coupons $(100 \times 150 \mathrm{~mm})$, there is no standardized test method for the laminate Compression After Impact (CAI) investigation, applicable at a higher level of the Building Block Approach. In this area, the scaled-up tests are performed in order to address not only the category 1 damage (barely visible impact damage or allowable manufacturing defects), but also visible impact damage with a significant delamination area, reaching up to $100 \mathrm{~mm}$ when it comes to LID (Large Impact Damage) [3]. To carry out these tests, and substantiate the structure is able to sustain certain design loads, the industry uses custom developed test fixtures, and the testing procedures that are usually proprietary.

Two test methods were considered for the purposes of this study: laminate loading in axial compression and sandwich 4-point flexure, where the compressed laminate skin is analyzed. Although both test methods did not fully met the requirements, the first one was mainly rejected due to buckling concern. The relatively simple and low-cost sandwich 4-point flexure test method, currently being developed by Adams [4] and recommended in [5] was selected.

The biggest challenge regarding the sandwich 4 point flexure test is to design the test element for which flexural failure is achieved. Core crushing, core shear or core to skin failure need to be avoided [6].

In Fig. 1 bending moment and shear force distribution in sandwich beam is presented. 


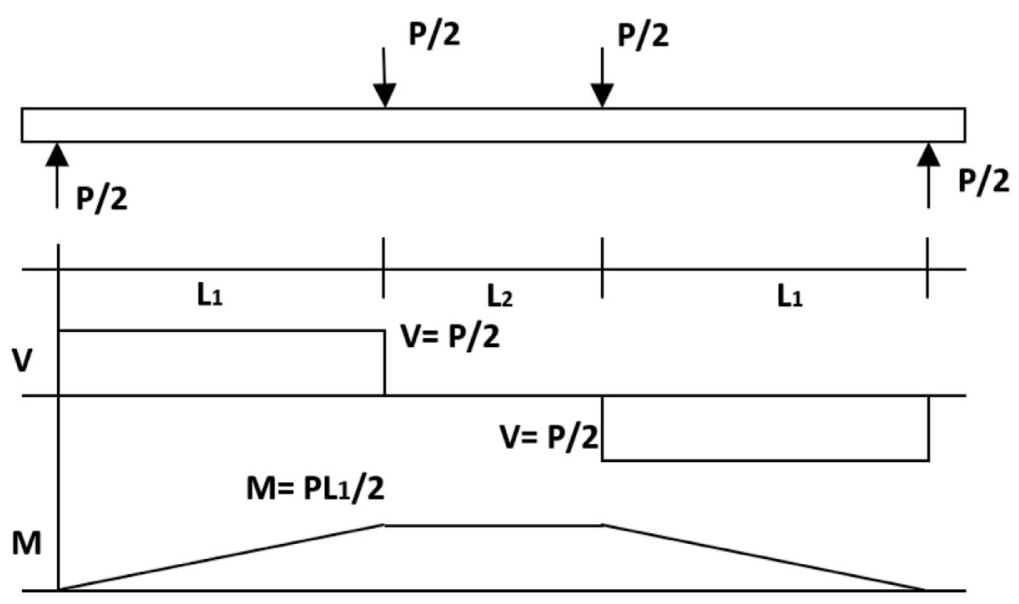

Fig. 1. Bending moment and shear force distribution.

In order to ensure the desired failure mode, the following factors are carefully analyzed: the test skin thicknesses and lay-up, honeycomb core material and density, loading span length, and the supporting span to thickness ratio. As it is given in [5] the most problematic is to obtain reference data, and achieve flexural failure for the elements without stress concentration due to hole, drilled in the central element section.

After performing the initial numerical calculation, the coupon dimensions, loading conditions and the laminates stacking sequence were defined. It was decided to use coupons with dimensions 560 x $100 \mathrm{~mm}$. The loading span length was equal to $100 \mathrm{~mm}$ while the supporting span was $500 \mathrm{~mm}$. The scheme of the element and the test set-up is presented in (Fig. 2).

a)
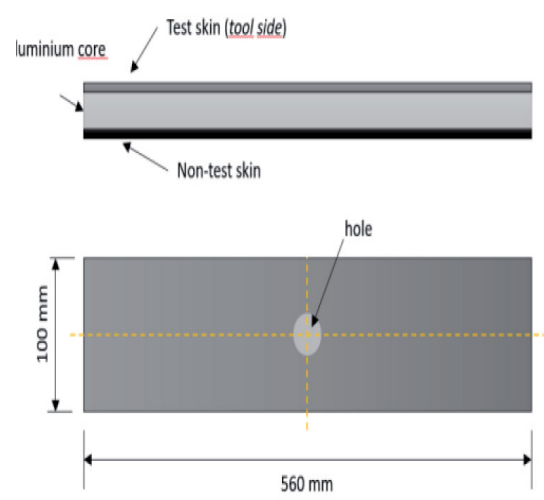

b)

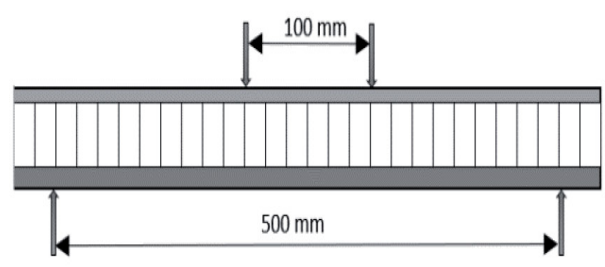

Fig. 2. Scheme of the test element (a) and Four-point flexure test set-up (b). 
The laminate consisted of 9 plies, with the nominal thickness of $1,36 \mathrm{~mm}$. The following stacking sequence $\left[45^{\mathrm{PW}} / 0^{\mathrm{UD}} / 0^{\mathrm{UD}} / 45^{\mathrm{UD}} / 90^{\mathrm{UD}} / 45^{\mathrm{UD}} / 0^{\mathrm{UD}} / 0^{\mathrm{UD}} / 45^{\mathrm{PW}}\right.$ ] was selected as the test laminate subjected to compressive loads. The non-test skin was built from 14 UD plies. To limit the probability of the core shear failure, the high density $130 \mathrm{~kg} / \mathrm{m}^{3}$ aluminum core was chosen.

\section{PREPARATION AND TESTING}

\subsection{Elements manufacturing}

For this experimental investigation, 3 test panels with the geometry of $600 \times 600 \mathrm{~mm}$ were built. Each panel consisted of 2 pre-cured laminate skins and the Plascore aluminum honeycomb core bonded together by Cytec 0,08 psf film adhesive. The skin panels were mainly manufactured with the Automated Fiber Placement (AFP) technology using Park carbon/epoxy prepreg. The Out of Autoclave (OoA) cure cycle, developed at the stage of material characterization, was applied. Once the panels quality was confirmed by the nondestructive inspection, they were cut for the testing elements by the saw with diamond coating. The holes of different diameters in the central area of the elements were milled on the $\mathrm{CNC}$ cutting machine.

\subsection{Static testing}

The first step of testing concerned static tests of the elements with various hole diameters (D). The tests were performed on the elements with four different holes: $6,35 \mathrm{~mm}, 10 \mathrm{~mm}, 20 \mathrm{~mm}$, and $50 \mathrm{~mm}$, milled in the central area of the compressed laminate. To generate the reference data, the element without a hole was also subjected to flexure loads. In order to prevent premature failure, rubber pads were placed under the $38 \mathrm{~mm}$ wide loading blocks. As was predicted, all the elements with the hole milled in the test laminate failed in flexure. The static failure load of the element without a hole was significantly higher, what resulted in the core shear failure mode.

Two different failure modes achieved in the static testing are presented in (Fig. 3).

a)

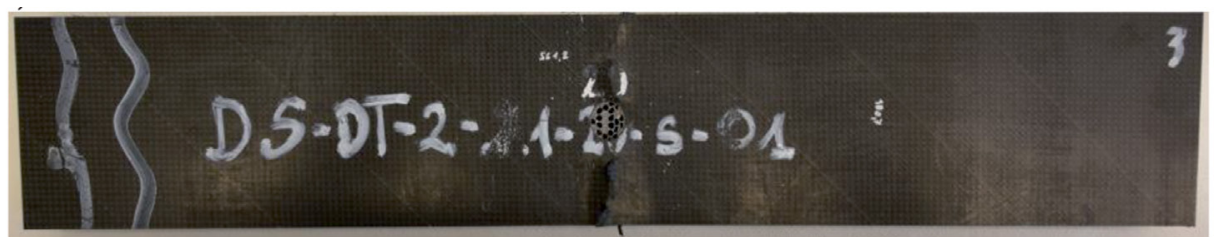


b)

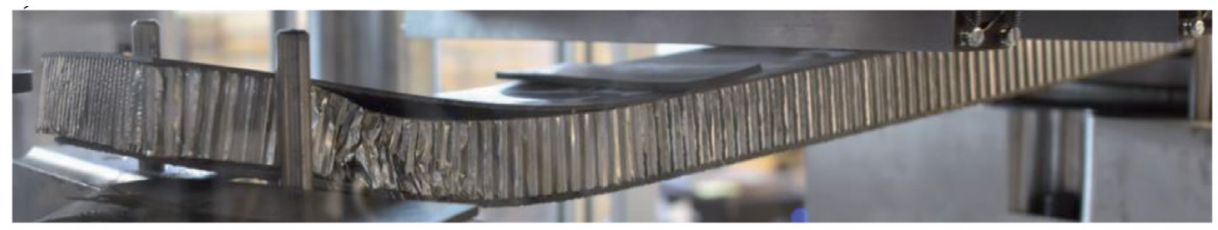

Fig. 3. Flexure failure mode (a) and core shear (b)

Fig. 4 shows the results obtained from the static tests. The fundamental of the analyze were the regulations [7], requiring that the structure having BVID should not fail under the design ultimate load (DUL), and the structure with a category 3 damage must sustain the design limit load (DLL). In this study, it was assumed that the $6,35 \mathrm{~mm}$ hole diameter represented barely visible impact damage (BVID) threshold, and the load under which the element with 6,35 $\mathrm{mm}$ hole diameter failed represented the DUL. Taking into account these assumptions, the failure load values were normalized to the value achieved for the element with a 6,35 hole diameter. Next, based on the 1,5 safety factor, DLL $(66,7 \%$ DUL) and the hole diameter equal to $35 \mathrm{~mm}$, representing the category 3 damage, were determined.

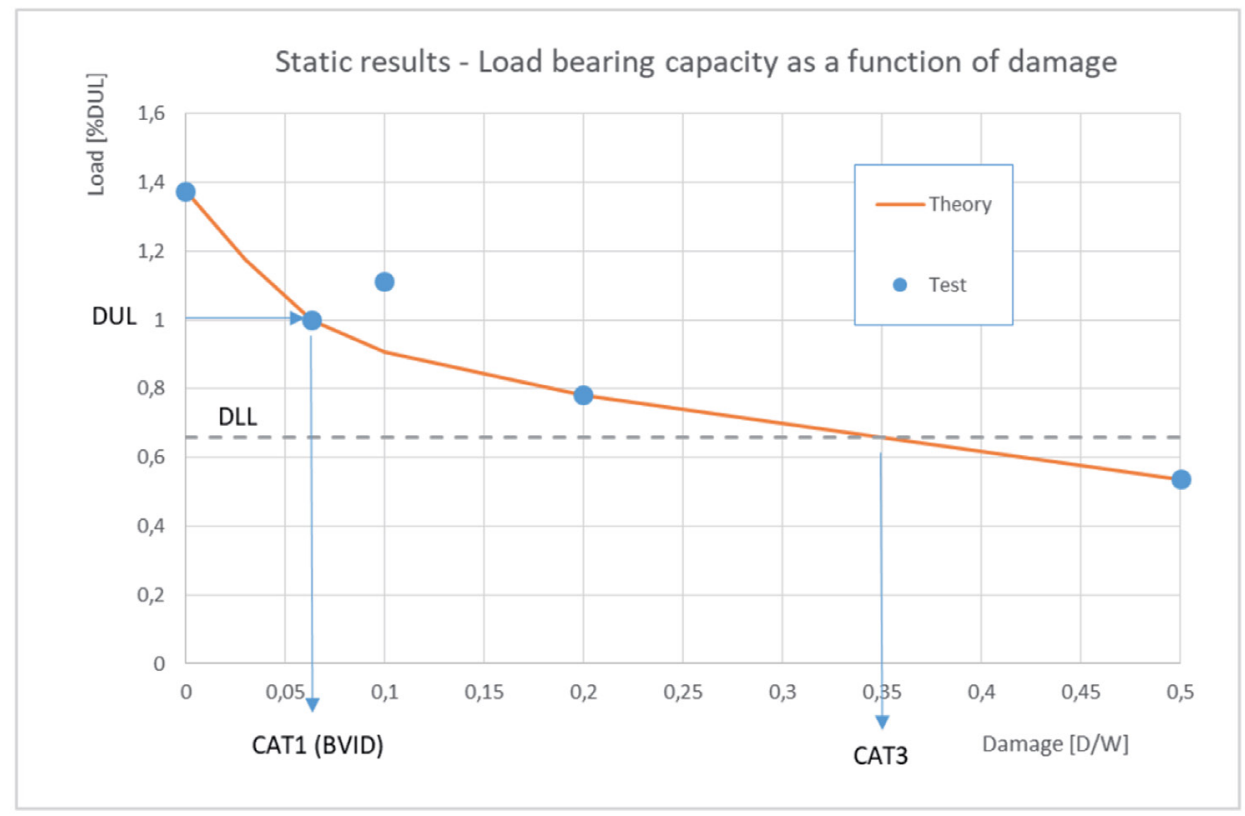

Fig. 4. Compressive failure load versus damage size (simulated by hole diameter) and ultimate and limit load values. 
Additionally to the elements with various holes, one element with a 1,3 dent depth impact damage was tested. The impact energy, resulting in a $1,3 \mathrm{~mm}$ dent depth was evaluated based on the impact survey carried out on the same structure configuration as the elements tested. Spherical impactors of 20,3 and $24,5 \mathrm{~mm}$ diameter were applied. Based on the calibration, which results along with the impact test set-up are visible in Fig. 5, the impactor diameter of 25,4 $\mathrm{mm}$ and the impact energy equal to $17 \mathrm{~J}$ were determined.



b)

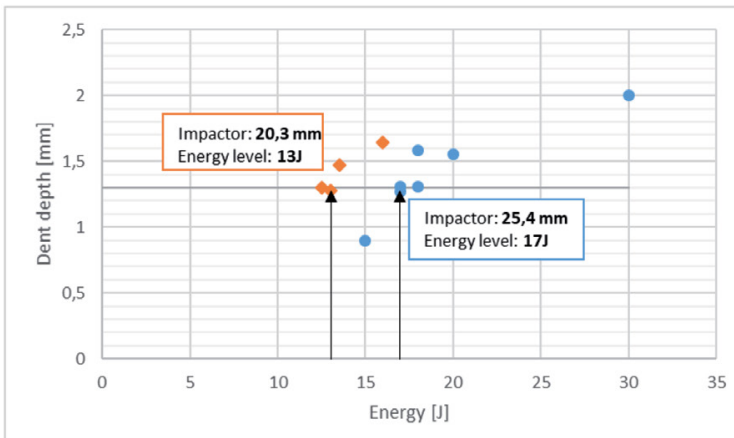

Fig. 5. Impact test set-up (a), and impact survey results (b).

Therefore the element with the damage was statically tested. Taking into consideration the delamination diameter, measured based on the NDI C-scan and equal to approximately $41,6 \mathrm{~mm}$, the linear distribution as presented in Fig. 6 was sustained.

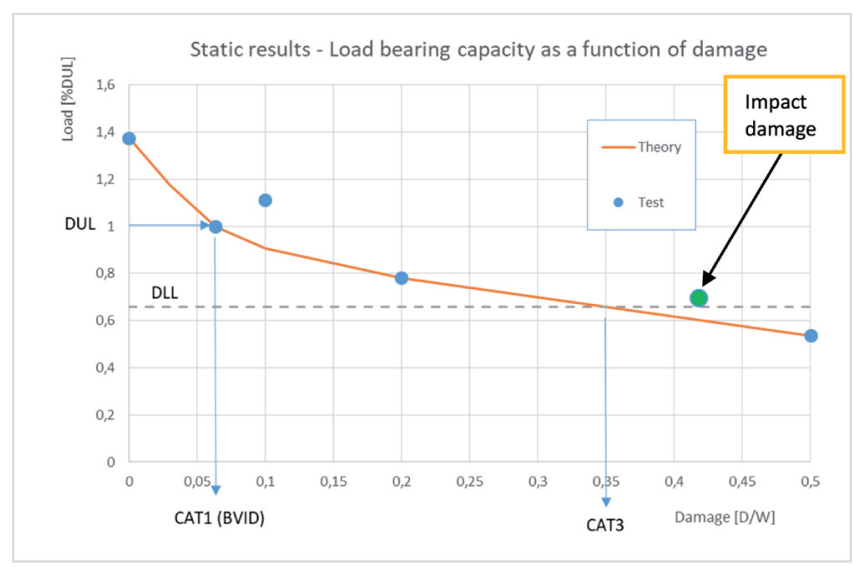

Fig. 6. Compressive failure load versus damage size (simulated by hole diameter and impact damage) and ultimate and limit load values. 


\subsection{Fatigue testing}

In the next step of the study, it was analyzed how two parameters: fatigue load level (phase 1) and hole diameter (phase 2) affected the laminate's fatigue performance. Each fatigue test was carried out with the constant amplitude compression-compression ( $\mathrm{C}-\mathrm{C}$ ), the stress ratio $\mathrm{R}=10$, and the frequency equal to $3 \mathrm{~Hz}$. It was assumed to test the elements up to 75000 cycles. When the element did not fail, the compressive residual load bearing capacity was investigated.

\subsubsection{Phase I - Effect of a fatigue load level on the laminate's durability}

In order to evaluate the influence of the cyclic loading amplitude on the laminate's fatigue life, it was decided to use the static failure load $(18,72 \mathrm{kN})$ of the element with a 6,35 diameter hole as the reference. The $6,35 \mathrm{~mm}$ hole, also present in the elements subjected to compressive fatigue loads, was supposed to characterize a barely visible impact damage that may appear in the structure (i.e. due to service), and for which the structure must sustain the ultimate design loads throughout its lifetime. Based on the test results, the laminate fatigue characteristic was created as presented in (Fig. 7).

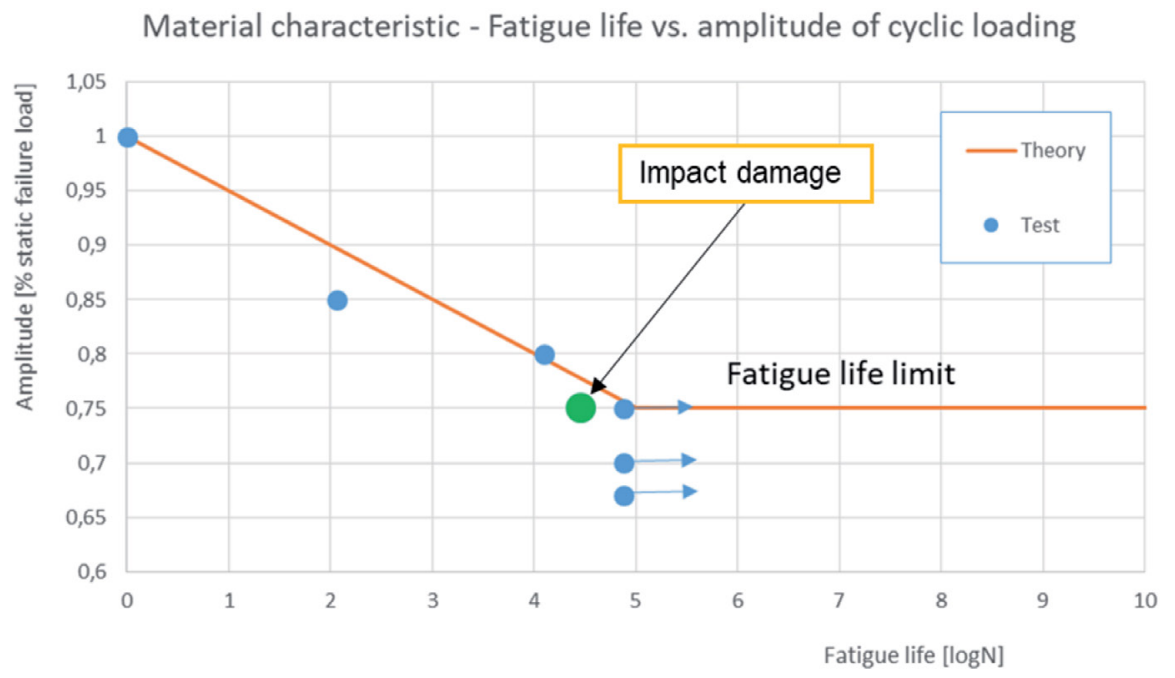

Fig. 7. Amplitude effect on the laminate's fatigue performance.

All elements that did not fail through 75000 cycles had a residual load bearing capacity similar to the static failure load. 
Table 1. Residual load bearing capacity in reference to static loads.

\begin{tabular}{|c|c|c|c|c|c|c|}
\hline Element ID & Hole diameter,D & Reference static load & Fatigue load & Fatigue load & Cycles, $\mathrm{N}$ & Residual load \\
\hline & $\mathrm{mm}$ & $\mathrm{kN}$ & $\%$ of static load & $\mathrm{kN}$ & - & $\mathrm{kN}$ \\
\hline 1 & 6,35 & 18,72 & $75 \%$ & 14,04 & 75000 & 19,76 \\
\hline 2 & 6,35 & 18,72 & $70 \%$ & 13,10 & 75000 & 18,15 \\
\hline 3 & 6,35 & 18,72 & $66,7 \%$ & 12,49 & 75000 & 19,78 \\
\hline
\end{tabular}

Based on that, the fatigue life limit of the laminate for which no influence of repeated loads was observed is $75 \%$ of the static loads. However, this statement is true only for elements with a 6,35 hole diameter. Having the impact damage, characterized by $1,3 \mathrm{~mm}$ dent depth, and a $36 \mathrm{~mm}$ delamination diameter, the element under $75 \%$ of the static loads sustained only 29000 cycles.

\subsubsection{Phase II - Effect of the hole diameter on the laminate's durability}

In the second phase of fatigue testing, the laminate with holes of various diameters $(6,35 ; 10 ; 20 ; 50 \mathrm{~mm})$ was subjected to constant amplitude compressive loads, equal to $66,7 \%$ of the DUL evaluated in the static testing. The results obtained along with the data achieved in the static and phase I fatigue testing allowed researchers to build the damage tolerance characteristic for the investigated laminate showed in Fig. 8.

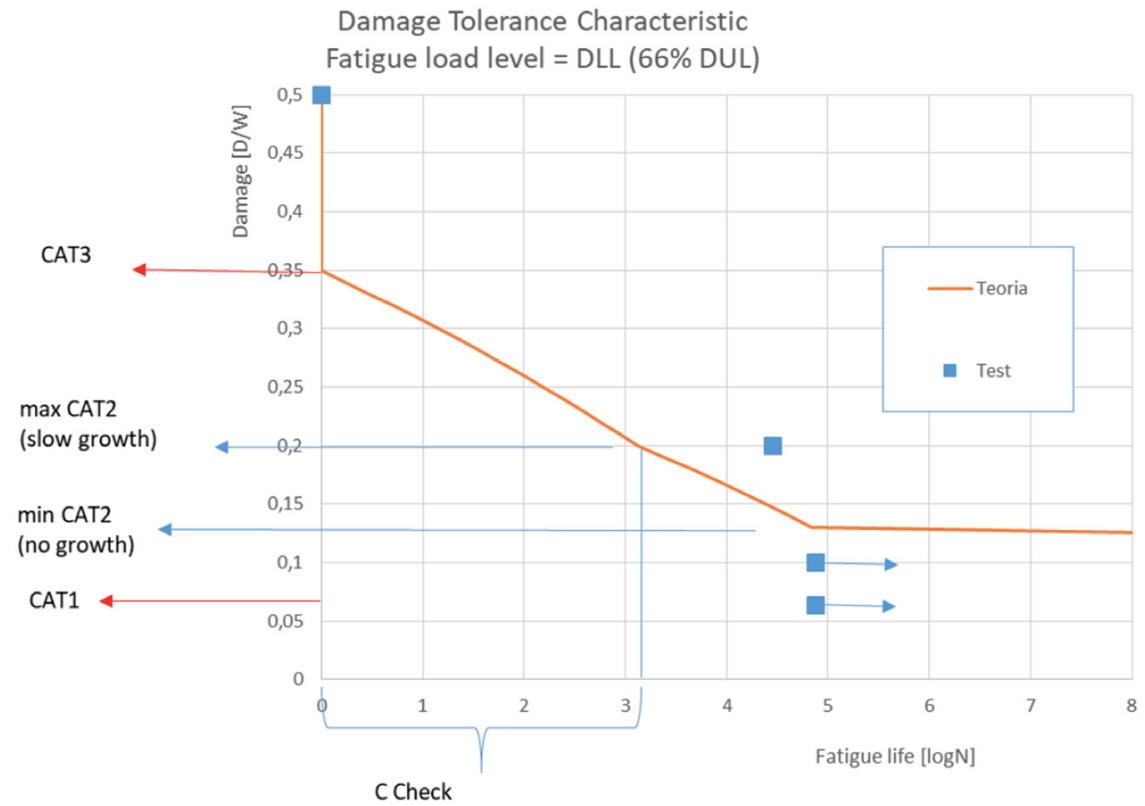

Fig. 8. Damage tolerance characteristic for the tested laminate. 
Based on Fig. 8, the considered laminate structure could be characterized as follows:

1) The laminate structure with a 6,35 hole diameter, considered in this study as the allowable damage limit (BVID threshold), is able to sustain the assumed DLL through the defined lifetime ( 75000 cycles).

2) Category 2 damage for the laminate structure is defined as a max. $20 \mathrm{~mm}$ hole diameter. This damage category needs to be detected during a normal inception process. The $\mathrm{C}$-check interval could be evaluated based on the damage characteristic and verified in further testing.

3) The critical damage threshold (max category 3 damage) for the laminate structure was defined as a $35 \mathrm{~mm}$ hole diameter. This damage category needs to be detected within a few flights of occurrence and repaired.

\section{CONCLUSIONS}

The study presented above led to the following conclusions:

1. Static test results show relatively low sensitivity of the laminate compression failure load to the stress concentration due to hole.

2. The test laminate exhibits a relatively high durability level. The fatigue load amplitude less than $75 \%$ of the $\mathrm{OHC}$ failure load causes no damage.

3. The performed tests made it possible to define the laminate through the damage tolerance characteristic.

4. Further testing in the scope of scatter analysis, tensile loading mode and impact damage, needs to be performed to fully understand the laminate's behavior.

\section{LITERATURE}

[1] Tomblin, J.S., Lacy, T., Smith, B., Hooper, S., Vizzini, A., Lee, S., Review of Damage Tolerance for Composite Sandwich Airframe Structures, Final Report, DOT/FAA/AR-99/49, 1999.

[2] CMH-17, Composite Materials Handbook, Volume 1. Polymer Matrix Composites Guidelines for Characterization of Structural Materials. SAE International, 2012.

[3] Tomblin J.S., Senevirante W. P., Durability And Damage Tolerance Testing of a Beechcraft Starship Forward-Wing With Large Damages, Final Report, DOT/FAA/TC-13/26, 2017.

[4] Adams D. O., Kuramoto B., Damage tolerance test method development for sandwich composites. 
[5] Gang Z., Leung H., Zheng C., Robinson B., New four-point bending based method for impact damage tolerance assessment of sandwich structure, Chinese Society for Composite Materials, 2017.

[6] ASTM standard D7249/D7249M, Standard Test Method for Facesheet Properties of Sandwich Constructions by Long Beam Flexure, ASTM International, 2018.

[7] European Aviation Safety Agency, 2010, AMC 20-29 Composite Aircraft Structure.

[8] ASTM standard ASTM D7137/D7137M, Standard Test Method for Compressive Residual Strength Properties of Damaged Polymer Matrix Composite Plates, ASTM International, 2017. 